Jurnal Keperawatan Padjadjaran

ISSN 2338-5324 (print)

ISSN 2442-7276 (online)

Online di http://jkp.fkep.unpad.ac.id

DOI : $10.24198 / \mathrm{jkp}$

\title{
Quality of Life among Patients Undergoing Haemodialysis in Bandung: A Mixed Methods Study
}

\author{
Kustimah Kustimah, Ahmad Gimmy Prathama Siswadi, Achmad Djunaidi, Aulia Iskandarsyah \\ Faculty of Psychology, Universitas Padjadjaran, Bandung, Indonesia \\ Correspondingemail:kustimah@unpad.ac.id
}

Submitted: 04-03-2020 Accepted: 26-04-2020 Published: 26-04-2020

\begin{abstract}
Quality of life (QoL) has become one of important outcome measures of renal replacement therapy, including haemodialysis. However, the assessment of QoL is not comprehensively measured and most research about it use quantitative approach. Since QoL is subjective, assessing and understanding the qualitative evidence are very important. This study aimed to explore QoL in patients with end-stage renal disease (ESRD) undergoing haemodialysis. This research is a cross-sectional study used a mixed method approach. Patients undergoing dialysis were recruited from the dialysis unit in one private hospital in Bandung. They completed the Kidney Disease and Quality of Life (KDQOL-36 $6^{\mathrm{TM}}$ ) questionnaire and then went on face to face interview. Quantitative data were analysed descriptively and qualitative data were analysed using thematic analysis with qualitative data analysis software. A total of 87 patients completed the questionnaires and 34 of them participated in 20-60 minutes interview. The symptom and problem list had the highest mean score $(M=M=63.60)$, indicated that patients experienced lack of energy, mobility and physical appearance that further produced difficulties in their daily activities. Additionally, mental component summary showed a higher mean score $(M=49.23)$ than the physical component $(M=36.22)$ indicated that patients most likely had worse mental health condition than their general physical health. Worse mental health condition induced with negative feeling among patients. Patient's inability to do daily activity and change in physical appearance had impact on their confidence for social relationship. Conclusion: ESRD patients undergoing haemodialysis were bothered by the symptom of illness and worsen by the negative feelings.
\end{abstract}

Keywords: End-stage renal disease, haemodialysis, mixed method, quality of life. 
Kustimah: Quality of Life among Patients Undergoing Haemodialysis in Bandung: A Mixed Methods Study

\section{Introduction}

Chronic kidney disease (CKD) is a serious global public health problem, affecting over 750 million persons worldwide (Bikboy, 2018). The number of patients with ESRD (End-stage renal disease) - the last and most serious stage (Pozzoni, 2014) - in Indonesia is continuously increasing. In 2017 the number of patients was 10,8723 ; rises to 19,8575 in 2018 and patients mostly (98\%) underwent haemodialysis (HD) as their treatment regimen (Indonesian Renal Registry, 2018).

While, HD effectively improve patients' life expectancy and quality of life (QoL) (Lee \& Bargman, 2016; Tannor et al, 2017; Dabrowska et al, 2018). It involves a complex procedure, requires them to frequently visit hospital or dialysis center, mainly two or three times a week, entails diet and fluid restrictions, and causes some HD related symptoms such as fatigue, decreased appetite, as well as muscle cramps that further lessen the patients' QoL (Avramovic \& Stefanovic, 2012; Cavalli et al, 2010; Landreneau \& Lee $\mathrm{K}, 2010)$. On the other hand, patients with ESRD had to adapt new lifestyle as results of the nature of the illness and the methods of its treatment.

Despite of the advancement of healthcare technologies, it is remains questionable whether or not patients who live longer always have a better QoL. QoL plays an important role in assessing patients' needs, setting the treatment goals, monitoring the disease progression, and developing plans of care that potentially improve patient care outcomes.

Some previous studies had attempted to explore QoL in patients with ESRD undergoing haemodialysis including in Indonesian setting. A study from Suwanti et al (2017) explains that more than half $(61.0 \%)$ ESRD patients who undergo haemodialysis had a poor QoL. Other research conducted by Mulia et al (2018) shows that patients had moderately good QoL. They displayed higher score in enviromental and social domains of quality of life than in physical and psychological domains. Most of existing studies on QoL only provided a quantitative information and lack of qualitative exploration about patient's quality of life. Since, QoL is subjective and unique matter for each patient, the assessment and understanding of qualitative aspects of QoL are very important. Although it is expensive and time consuming, incorporating qualitative methods generates more through information. Qualitative data enable researchers to generate rich data from the perspective of patients about their QoL (Tonon, G, 2015; Kim, Sefcik \& Bradway, 2017).

Mixed method is powerful approach when addressing complex, multifaceted issues, such as living with chronic illnesses (Nicca, 2012). This approach signifies both quantitative and qualitative data that then potentially provide more comprehensive explanation of a phenomenon. This mixed methods study designed to comprehensively investigate the QoL of patients with ESRD undergoing haemodialysis in Bandung.

\section{Method}

We conducted a cross-sectional study using sequential explanatory model. This model consisted of two phase, first collecting quantitative data and then gather a qualitative data to help deepen the finding in quantitative phase (Cresswel, 2014). Patients undergoing haemodialysis were recruited from the dialysis unit of one private hospital in Bandung, Indonesia from June 2017 to March 2018. Samples who meet the inclusion criteria were selected by convenient sampling. The inclusion criteria were as follows: (1) confirmed diagnosis of ESRD from medical record (2) patients at least 18 years old, (3) on regular haemodialysis therapy for a minimum of 6 months. The patients were excluded if they lacked the physical and mental capacity to communicate with the interviewer.

Nephrologist and nurse screened patients who met the criteria and gave the list to the researcher. Then researcher approached the patients to explain the details of the current study and asked their willingness to participate. Once they agree to participate in this study, the researcher asked them to sign the informed consent form. Patients were also asked their willingness to be interviewed, and those who agreed were scheduled for interview. 
The current study was approved by the Research Ethics Committee of Universitas Padjadjaran under the ethical certificate No. 349/UN6.KEP/EC/2018. Each participant was well informed of the content and the aim of the research.

The Kidney Disease and Quality of Life (KDQOL-36 ${ }^{\mathrm{TM}}$ ), a self-reported questionnaire that combines the generic SF36 Health Survey Instrument and diseasespecific components for assessing the healthrelated QoL of patients with chronic kidney disease was used to measure QoL among ESRD patients in this study. We accesed the questionnaire from RAND health and downloaded it from RAND corporation website. KDQOL-36 $6^{\mathrm{TM}}$ focused on the underlying health status during the preceding 4 weeks. It consists of 36-item survey with five subscales: (1) symptom and problem list (2) effects of kidney disease (3) burden of kidney disease (4) physical component summary (PCS) and (5) Mental component summary. There were 24 items asking about disease-specific cores: symptom and problems (12 items), burden of kidney disease (4 items), and effects of kidney disease ( 8 items). Additionally, there were 12 items of the generic core adopted from SF-12 instruments, which were divided into the physical component summary (PCS) (8 items) and the mental component summary (MCS) (4 items) (Hays et al, 1994).

The adaptation process used the forward and back translation by two bilingual psychologists to prepare the Indonesian version of KDQOL-36TM. The Cronbach Alpha coefficient was examined on the subscales to determine internal consistency. The Cronbach's alpha for each subscale of the Indonesian version of the KDQOL-36TM in the current sample is as follows: physical functioning $=0.743$, mental functioning $=$ 0.579 , burden of kidney disease $=0.763$, symptom/problems $=0.797$ and effect of kidney disease $=0.801$.

Validity based on content was provided by using Focus Group Discussion (FGD) with patients, nephrologist and nurse on haemodialysis unit to assess the clarity, relevance and interpretation of each item in KDQOL-36TM scale. Each proxy could give a feedback about the questionnaire until we achieved some degree of consensus and the Indonesian version of KDQOL-36TM scale was finalized.

The qualitative data were collected through 20-60 min interviews with 34 participants. A semi-structured interview technique was utilized to acquire information from the participants. The participants were interviewed on the following : (1) Exploration of how the illness symptoms affect patient's daily life and (2) The impacts of illness and treatment on patients' psychological conditions. Research assistant with background of psychology will conduct data collection. They are three master students from clinical psychology program who first received a 2-day training session by the researcher. The training covered information about (1) quality of life in patient who undergoing haemodialysis, (2) general interview techniques and (3) how to administer the data. Quantitative data were analysed descriptively; raw scores on KDQOL-36TM were transformed to a score ranging from 0 to 100 with higher score representing worse perceived QoL. Demographic data are presented as frequencies and percentages while score of QoL presented as mean and standard deviation (SD).

In qualitative phase, all interviews were audiotaped and transcribed verbatim in word document. Researcher and two coders with psychologist background analysed the data using thematic analysis (Bradley, 2007) with qualitative data analysis software to identify recurring patterns in the transcript (Vaismoradi M, 2013).

\section{Results}

A total of 87 patients with ESRD were recruited from the haemodialysis unit of a private hospital. On the basis of the demographic and clinical characteristics, 44 patients were male and 43 patients were female, age ranged from 18 to 77 years old $(\mathrm{M}=43.9, \mathrm{SD}=14.115)$, mostly married, finished high school, and unemployed or as a housewife. Majority of them were undergoing dialysis twice a week and the common causes of kidney disease were hypertension and diabetes mellitus. An overview of the socio- 
Kustimah: Quality of Life among Patients Undergoing Haemodialysis in Bandung: A Mixed Methods Study

Table 1 Demographic and Clinical Characteristics of Study Participants

\begin{tabular}{|c|c|c|}
\hline Variables & $\mathbf{n}$ & Percentage $(\%)$ \\
\hline \multicolumn{3}{|l|}{ Gender } \\
\hline Male & 44 & 50.6 \\
\hline Female & 43 & 49.4 \\
\hline \multicolumn{3}{|l|}{ Age Range } \\
\hline$\leq 35$ & 28 & 32.2 \\
\hline $36-50$ & 29 & 33.3 \\
\hline $51-65$ & 24 & 27.6 \\
\hline$\geq 65$ & 6 & 6.9 \\
\hline \multicolumn{3}{|l|}{ Marital Status } \\
\hline Single & 10 & 11.5 \\
\hline Married & 74 & 85.1 \\
\hline Widowed & 3 & 3.4 \\
\hline \multicolumn{3}{|l|}{ Education } \\
\hline Junior High School & 6 & 6.8 \\
\hline Senior High School & 45 & 51.7 \\
\hline College & 36 & 41.4 \\
\hline \multicolumn{3}{|l|}{ Employment } \\
\hline Housewife/unemployed & 46 & 52.9 \\
\hline Employed & 36 & 41.4 \\
\hline Retired & 5 & 3.7 \\
\hline \multicolumn{3}{|l|}{ Duration on dialysis (months) } \\
\hline$<12$ months & 21 & 24.1 \\
\hline $1-3$ years & 40 & 46 \\
\hline $4-6$ years & 16 & 18.4 \\
\hline$>7$ years & 10 & 11.5 \\
\hline \multicolumn{3}{|l|}{ Frequency Dialysis per week } \\
\hline Once a week & 4 & 4.6 \\
\hline Twice a week & 83 & 95.4 \\
\hline \multicolumn{3}{|l|}{ Cause of kidney disease } \\
\hline Diabetes Mellitus & 10 & 11.5 \\
\hline Hypertension & 55 & 63.2 \\
\hline $\begin{array}{l}\text { Any other causes (lupus, self-medications, unhealthy diet/ } \\
\text { drink, etc.) }\end{array}$ & 22 & 25.3 \\
\hline
\end{tabular}

Table 2. Scores for each Dimension of QoL in ESRD Patients

\begin{tabular}{ll}
\hline \multicolumn{1}{c}{ Dimensions } & Score \\
\hline Symptom/Problems List & $63.60 \pm 17.60$ \\
Effect of Kidney Disease & $58.91 \pm 19.72$ \\
Burden of Kidney Disease & $49.13 \pm 23.73$ \\
Physical Component Summary & $36.22 \pm 8.02$ \\
Mental Component Summary & $49.23 \pm 8.95$ \\
\hline
\end{tabular}


demographic data and clinical characteristics of the study participants is presented in the table below.

\section{Quantitative data of QoL}

The mean score and standard deviation for each dimension of QoL was listed in Table 2. The symptom and problem list had the highest mean score $(\mathrm{M}=63.60)$ of the 5 subscales on the KDQOL-36TM. It can be interpreted that ESRD patients reported feeling very bothered by the symptoms of kidney disease and problem related to the symptoms. They were aggravated by fatigue, sore muscles, chest pain, itchy, dry skin, shortness of breath, lack of appetite and problem with access to dialysis.

Patients were also displeased by the effect of kidney disease in their daily life; such as fluid and diet restriction, ability to travel, work and dependency on dialysis treatment. The lowest mean score found in burden of kidney disease subscale $(M=49.13)$, which mean patients perceive that their illness cause interference in their daily life, frustration, takes up more time and makes them feel like a burden.

The assessment of patient's overall health, mental component summary $(\mathrm{M}=49.23)$ showed a higher score than the physical component $(\mathrm{M}=36.22)$. It can be said that patients most likely had worse mental health condition than their general physical health. Patients most likely have worse mental health condition which encompass feeling such as fear, sadness and frustration. In general physical health, even though the patient has decreased energy levels caused by the effect of the illness, the patients can still do some level of mild physical activity.

\section{Qualitative phase}

A total of 34 participants (20 females and 14 males) took part in the interview session. The participants were selected conveniently according to their accessibility and willingness to participate in this study. Their mean age was 48.17 years (range $25-$ 77 years). The mean duration of hemodialysis was 32.24 months (range 6-84 months), and all of them were undergoing dialysis twice a week. The result of this phase was summarized in three themes: (1) decrease energy levels and mobility, (2) social relationships, and (3) negative feeling. These themes will be elaborated in the remaining part of this section.

\section{Decreased energy levels and mobility}

Decreased energy levels impacted the lives of patients. The majority of patients can only spend their time at home because they felt weak, fatique and less energized. Many female patients $(52.9 \%)$ chose to be housewife and just worked on light house chores, such as sweeping and washing dishes. All male patients $(50.6 \%)$ were unproductive to be at work and chose early retirement. This low working capacity is caused by many symptoms, such as breathlessness, itches, nausea, lack of appetite, and difficulties to walk because of edema. The interrelationship between decreased energy levels and mobility is illustrated:

"My stamina is almost $80 \%$ decrease compared to before I fell ill, now I couldn't go to work. I chose early retirement and spend my days at home every day. For 24 hours, my body feels bad, sitting is wrong and sleeping isn't good. I have frequent decline in health conditions, so I can't go anywhere" (M, 56 years).

"Since I was sick I applied for early retirement ... don't even go to work, for daily activities I often feel tired. I could not drive because I had passed out on the road. Now I'm just at home ... accompanied by oxygen tanks cylinders because of frequent shortness of breath too. Now I have difficulty walking ... swollen legs ... cause of excess drinking" ( $\mathrm{F}, 61$ years)

Loss of energy and decline in mobility might explain the greater perceived symptom and problem related to kidney disease by the patients. This finding also suggested how kidney disease could severely impact patient's physical condition to the point they were unable to do things they used to do.

\section{Social relationships}

Physical changes experienced by patients, such as blackened skin, weight loss, and scarring, affected the patient's level of confidence for social relationships.

"I'm embarrassed. People like to take selfies when they meet up nowadays. I feel 
Kustimah: Quality of Life among Patients Undergoing Haemodialysis in Bandung: A Mixed Methods Study

ugly and unattractive. I look older than my age too. (I'm) skinny, pale, and I don't look good in photos. Others look good and happy in photos... I can't do that." (F, 29 years)

"Since I was ill, I've become very thin. My skin grew dry and darker. So, I have to wear long-sleeved clothes to cover the fistula. They are ugly, as big as eggs. I'm not confident in my appearance" (M,31 years)

\section{Negative feeling}

The patients in the beginning of undergoing dialysis had many negative feelings, such as fear, sadness, anxiety and frustration. Haemodialysis treatment was done because "there is no other choice." Although it is important, it has become a burden because the treatment is very painful.

"For me, what bothers me the most is that I have to undergo dialysis for the rest of my life. It makes me anxious and feel like an invalid because my life is supported by machine." (M, 27 years)

Depression was a common psychological response. Majority of the patients expressed feelings of depression, namely, thoughts about death and hopelessness, as described by one patient:

"If I remember how miserable is, I thought about wanting to die faster. But I'm very anxious... afraid of death, ... afraid of the sins. Worries that always appear to me is if anytime 'I'm taken away'. If I remember how difficult it is to manage my health, I feel hopeless and I want everything to 'end'. But the thought that present time is 'waiting time' and there is 'empty seat' which ready to be 'filled' whenever God wills. It makes me often feel sad and doing a lot of daydreaming." (M, 29 years)

It is understandable if the patients experienced more negative feelings caused by their health condition. Physical conditions, which often decrease, made patients visit the hospital back and forth. This scenario raised negative comments from others on patients who made them feel sad. This following statement describes a patient's experience regarding this matter:

"I feel sad if I listen to other people comment about kidney disease is incurable illness, will get sick for the rest of my life. If my condition is dropping and need to be treated in emergency room, there is always someone commenting "why are you always sick?" (F, 36 years)

All patients were given social support by caregivers, including family member, spouse, and children. Although all patients found that family is a source of energy to live, the support given by the family has an ambiguous feeling. It was perceived as social support by the patients, but they felt guilty because they became a burden to the family on the other hand.

"Family, husband, children, and grandchildren are very supportive about getting treatment regularly. Even my nephew likes to remind me and offer a help to accompany to the hospital. But I always feel to be a burden on my family. Especially to my husband, his income always run out and spend on medication, we can't save money like we're used to, I also feel guilty about not being able to perform my duties as a wife and a mother due to the illness" (F, 43 years)

Patients need support from their family because they have regular schedule for hospital visit to do haemodialysis. The long treatment regimen and the constant need to be helped by caregivers could make them feel like burden. Other than that, patient's health condition often worsen over time so they need more attention from their family.

"I feel like I'm a burden to my family for always needing to be taken back and forth for hemodialysis session every twice a week. My son takes me even when he has work. Especially when I can't breathe, he must ready to take me to the E.R." (F,59 years)

\section{Discussion}

Studies show that dialysis is a life-saving treatment, but is often burdensome to ESRD patients, with potentially serious impacts on QoL (Wan et al., 2015). In this study, QoL was defined as a multiple-dimension concept that concerns an individual's usual or expected physical, emotional, and social well-being.

Regarding the domains of QoL, we found that the symptom and problem list had the highest mean score of the 5 subscales on the KDQOL-36TM. Symptom and problem list described how bothered patients feels in daily 
Kustimah: Quality of Life among Patients Undergoing Haemodialysis in Bandung: A Mixed Methods Study

life. ESRD patients reported feeling very bothered by the symptoms of kidney disease and problem related to the symptoms. Patients bothered by sore muscles, fatigue, chest pain, cramps, itchy or dry skin, shortness of breath, faintness/dizziness, lack of appetite, feeling washed out or drained, numbness in the hands or feet, nausea or problems with dialysis access (Veerappan et al, 2012).

From the results of the interview, we also discover that fatique emerged as one of the most persistent and debilitating symptoms. Fatique were expressesed as decrease stamina and low working capacity by the patients. Fatigue is a complex and subjective symptom characterised by extreme and persistent tiredness resistant to rest and recuperation. Fortynine to $92 \%$ of dialysis patients suffer from fatigue (Al Mutary, 2013). This condition caused patients feel weak and less energized. It also restricted the ability of patients to perform many activities. They have a limitation in physical activity, especially work related activities that require physical strength and stamina. This result is in line with the previous findings that fatigue is one of the most common and disabling symptoms which can lead to deflation of daily physical activity and physical performance among patients undergoing haemodialysis (Kopple et al, 2015).

This study also showed that the effect of kidney disease bothered in daily life; patient should fluid limit, diet restriction and should attendance haemodialysis session every week. It can be interpreted that patients had to adapt new lifestyle as results of the nature of the illness. A typical haemodialysis patient will be required to attend dialysis sessions 2-3 times a week for 3-4 hours each time. (Mactier, Hoenich \& Breen, 2009) and adherence to dietary recommendations, fluid restriction and prescribed medications, are essential for optimal and effective treatment of patients with ESRD undergoing haemodialysis (Kugler, Maeding \& Russel, 2011). Patients need social support, especially from family, spouse and also friends (Mailani, 2015). Based on the interview results, we found that the new life style cause patients feel burdened and guilty toward their family who have to go back and forth to take them to the hospitals in order to get treatments.
The assessment of patients' general health, mental component showed that patients had many negative feeling such as fear, sadness, and also expressed anxiety feeling. Negative emotional state characterized by somatic and cognitive symptoms including feelings of sadness and worthlessness, those descriptions were typical mental symptoms in ESRD patients (Palmer et al, 2013). Research from Patimah et al (2015) and Alamsah et al (2018) explains that patients undergoing haemodialysis experience anxiety. Other research demonstrates that QoL of patients with ESRD is mostly affected by living in fear of dying and experiencing stress due to anxiety about the future and their families, disease outcome, and shortened life span (Xhulia et al, 2016). In this study, the patients also verbalized that negative feeling may related to the changes in their body thus make them have negative perception about their physical appearance. Patients expressed feeling bothered by the changes in their body image as a result of side effects from their treatment that affected their confidence in social relationship.

\section{Conclusion}

Our study found that QoL of ESRD patients who undergoing haemodialysis bothered physically and mentally because of their illness. Physically, patients disturbed by the symptoms of the illness, burden of living with thus illness and the effect of the kidney disease. All of them inhibited patients to do their daily activities. They also experienced psychological effect of the illness such as negative feelings. The finding from quantitative phase also explained by our finding from qualitative phase.

\section{Limitations}

This finding cannot be generalized to the larger population of ESRD patient due to the limited sample population examined. In this study clinical and laboratory parameters that related to QoL of patients were not measured. In next study, clinical studies are needed to assess clinical factors determining QoL, as they can serve as baseline data to develop QoL intervention for improving the QoL related to patients' physical and psychological 
Kustimah: Quality of Life among Patients Undergoing Haemodialysis in Bandung: A Mixed Methods Study

conditions.

\section{Acknowledgement}

We would like to thank all of the participants who helped conduct the present study. We are also thankful to the research assistants who helped the researcher in data collecting process.

\section{References}

Alamsah, M. S., Rahayuwati, L., \& Purba, C. I. H. (2018). The effects of sundanese kacapi suling "ayun ambing" music therapy to the level of anxiety on chronic renal failure patient undergoing hemodialysis. Jurnal Keperawatan Padjadjaran, 6(1). https://doi. org/10.24198/jkp.v6i1.390

Almutary, H., Bonner, A., \& Douglas, C. (2013). Symptom burden in chronic kidney disease: a review of recent literature. Journal of Renal care, 39(3), 140-150. https://doi. org/10.1111/j.1755-6686.2013.12022 .x

Avramovic, M., \& Stefanovic, V. (2012). Health-related quality of life in different stages of renal failure. Artificial organs, 36(7), 581589. https://doi.org/10.1111/j.1525-1594. 2011.01429. x

Bikbov, B., Perico, N., \& Remuzzi, G. (2018). Disparities in chronic kidney disease prevalence among males and females in 195 countries: analysis of the Global Burden of Disease 2016 Study. Nephron, 139, 313-318. https://doi.org/10.1159/000489897

Bradley, E. H., Curry, L. A., \& Devers, K. J. (2007). Qualitative data analysis for health services research: developing taxonomy, themes, and theory. Health services research, 42(4), 1758-1772. https://doi.org/10.1111/ j.1475-6773.2006.00684.x

Cavalli, A., Del Vecchio, L., Manzoni, C., Locatelli, F., \& Del Vecchio, L. (2010). Hemodialysis: yesterday, today and tomorrow. Minerva Urol Nefrol, 62(1), 1-11. Retrieved September 11, 2020, from https:// pubmed.ncbi.nlm.nih.gov/20424566/
Creswell, J. W. (2014). A concise introduction to mixed methods research. SAGE publications.

Dąbrowska-Bender, M., Dykowska, G., Żuk, W., Milewska, M., \& Staniszewska, A. (2018). The impact on quality of life of dialysis patients with renal insufficiency. Patient preference and adherence, 12, 577. https://doi.org/ 10.2147/PPA.S156356

Hays, R. D., Kallich, J. D., Mapes, D. L., Coons, S. J., \& Carter, W. B. (1994). Development of the kidney disease quality of life (KDQOL TM) instrument. Quality of life Research, 3(5), 329-338. https://doi. org/10.1007/bf00451725

Indonesia, P. N. (2018). 10 th report of Indonesian renal registry. Pernefri..

Kim, H., Sefcik, J. S., \& Bradway, C. (2017). Characteristics of qualitative descriptive studies: A systematic review. Research in nursing \& health, 40(1), 23-42. https://doi. org/10.1002/nur.21768

Kopple, J. D., Kim, J. C., Shapiro, B. B., Zhang, M., Li, Y., Porszasz, J., ... \& KalantarZadeh, K. (2015). Factors affecting daily physical activity and physical performance in maintenance dialysis patients. Journal of renal nutrition, 25(2), 217-222. https://doi. org/10.1053/j.jrn.2014.10.017

Kugler, C., Maeding, I., \& Russell, C. L. (2011). Non-adherence in patients on chronic hemodialysis: an international comparison study. Journal of nephrology, 24(3), 366. https://doi.org/10.5301/JN.2010.5823

Landreneau, K., Lee, K., \& Landreneau, M. D. (2010). Quality of life in patients undergoing hemodialysis and renal transplantation-a meta-analytic review. Nephrol Nurs J, 37(1), 37-44. Retrieved October 3, 2019, from https://pubmed.ncbi.nlm.nih.gov/20333902/

Lee, M. B., \& Bargman, J. M. (2016). Survival by dialysis modality-who cares? Clinical journal of the American Society of Nephrology, 11(6), 1083-1087. https://doi. org/10.2215/CJN.13261215 
Kustimah: Quality of Life among Patients Undergoing Haemodialysis in Bandung: A Mixed Methods Study

Mactier, R., Hoenich, N., \& Breen, C. (2009). The Renal Association-haemodialysis guidelines. The Renal Association.

Mailani, F., Setiawan, S. \& Cholina, T.S. (2015). Pengalaman spiritualitas pada pasien penyakit ginjal kronik yang menjalani Hemodialisa. (Spiritual experience in chronic kidney disease patients undergoing Hemodialysis). Jurnal Keperawatan Padjadjaran, 3(1), 11-17. https://doi. org/10.24198/jkp.v3i1.94

Mulia, D. S., Mulyani, E., Pratomo, G. S., \& Chusna, N. (2018). Kualitas Hidup pasien gagal ginjal kronis yang menjalani hemodialisis di RSUD Dr. Doris Sylvanus Palangka Raya. . (Quality of life of chronic kidney failure patients undergoing hemodialysis at Dr. Doris Sylvanus Palangkaraya). Borneo Journal of Pharmacy, 1(1), 19-21. https://doi.org/10.33084/bjop. v1i1.238

Nicca, D., Fierz, K., Happ, M. B., Moody, K., \& Spirig, R. (2012). Symptom management in HIV/AIDS: a mixed methods approach to describe collaboration and concordance between persons living with HIV and their close support persons. Journal of Mixed Methods Research, 6(3), 217-235. https:// doi.org/10.1177/1558689811421773

Palmer, S., Vecchio, M., Craig, J. C., Tonelli, M., Johnson, D. W., Nicolucci, A., ... \& Strippoli, G. F. (2013). Prevalence of depression in chronic kidney disease: systematic review and meta-analysis of observational studies. Kidney international, 84(1), 179-191. https://doi.org/10.1038/ ki.2013.77

Patimah, I., Suryani, S., \& Nuraeni, A. (2015). Pengaruh relaksasi dzikir terhadap tingkat kecemasan pasien gagal ginjal kronis yang menjalani hemodialisa. (The effect of dhikr relaxation on anxiety levels in chronic kidney failure patients undergoing hemodialysis). Jurnal Keperawatan Padjadjaran, 3(1). https://doi.org/10.24198/jkp.v3i1.95

Pozzoni, P., Del, L. V., Pontoriero, G., Di, S.
F., \& Locatelli, F. (2004). Long-term outcome in hemodialysis: morbidity and mortality. Journal of nephrology, 17, S87-95.

Suwanti, S., Wakhid, A., \& Taufikurrahman, T. (2019). Gambaran kualitas hidup pasien gagal ginjal kronis yang menjalani terapi hemodialisa. (Overview of the quality of life of patients with chronic kidney failure undergoing hemodialysis therapy). Jurnal Keperawatan Jiwa, 5(2), 107-114.

Tannor, E. K., Archer, E., Kapembwa, K., Van Schalkwyk, S. C., \& Davids, M. R. (2017). Quality of life in patients on chronic dialysis in South Africa: a comparative mixed methods study. BMC nephrology, 18(1), 4. https://doi.org/10.1186/s12882-016-0425-1

Tonon, G. (Ed.). (2015). Qualitative studies in quality of life: Methodology and practice (Vol. 55). Springer.

Vaismoradi, M., Turunen, H., \& Bondas, T. (2013). Content analysis and thematic analysis: Implications for conducting a qualitative descriptive study. Nursing \& health sciences, 15(3), 398-405. https://doi. org/10.1111/nhs. 12048

Veerappan, I., Arvind, R. M., \& Ilayabharthi, V. (2012). Predictors of quality of life of hemodialysis patients in India. Indian journal of nephrology, 22(1), 18. https://dx.doi. org/10.4103\%2F0971-4065.91185

Wan, E. Y., Chen, J. Y., Choi, E. P., Wong, C. K., Chan, A. K., Chan, K. H., \& Lam, C. L. (2015). Patterns of health-related quality of life and associated factors in Chinese patients undergoing haemodialysis. Health and quality of life outcomes, 13(1), 108. https:// doi.org/10.1186/s12955-015-0308-3

Xhulia, D., Gerta, J., Dajana, Z., Koutelekos, I., Vasi-lopoulou, C., Skopelitou, M., \& Polikandrioti, M. (2016). Needs of hemodialysis patients and factors affecting them. Global journal of health science, 8(6), 109. https://doi.org/10.5539/gjhs.v8n6p109 